
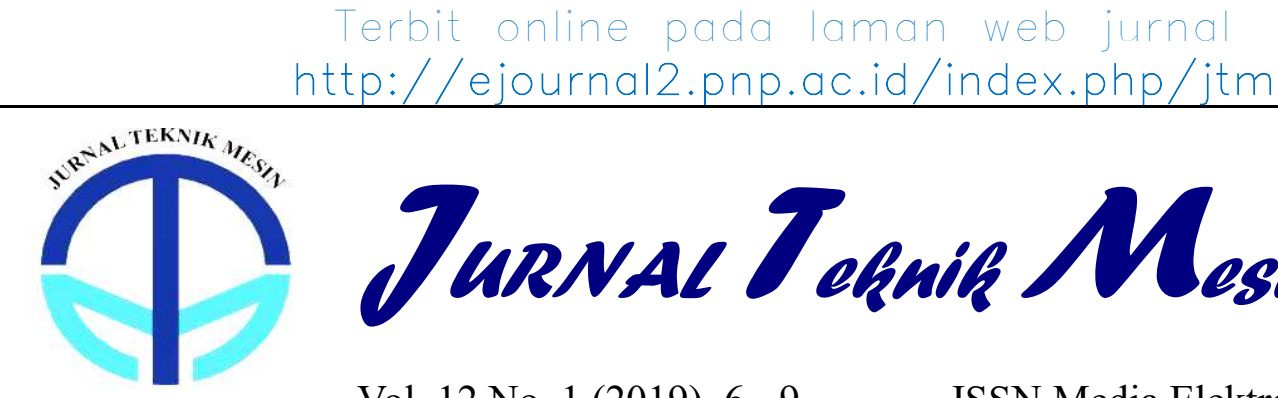

JuRval Tequili Mesin

POLITEKNIK NEGERI PADANC

Vol. 12 No. 1 (2019) 6 - 9

ISSN Media Elektronik: 2655-5670

\title{
Perakitan Sensor Asap Pada Alat Penyaring Asap Untuk Mengontrol Fan Secara Otomatis
}

\author{
RozyAdityaWiratama ${ }^{1}$, Rakiman $^{2}$, EkaSunitra $^{3}$ \\ ${ }^{12,3}$ Teknik Mesin,Politeknik Negeri Padang \\ ${ }^{2}$ Rakiman@pnp.ac.id ${ }^{3}$ EkaSunitra@pnp.ac.id
}

\begin{abstract}
Starting from the events on the island of Sumatra that often experience forest fires and result in the emergence of smog that can disrupt the respiratory tract in living things, especially in humans. Thus resulting in the emergence of diseases such as ispa, shortness of breath, and other diseases. This is caused by polluted air because the concentration of oxygen (O2) is only a few percent compared to air containing carbon dioxide (CO2), carbon monoxide (CO), sulfide (S2) and other combustion substances. The smoke sensor is useful for activating the fan on the smoke filter tool automatically, the Fan functions as a smoke suction to be forwarded to the room where the smoke is filtered. The workings of this tool are, when the sensor reads the smoke content on the tool more than $140 \mathrm{ppm}$, then the relay connected to the fan will activate and make the fan spin. After the fan or fan lives, then the smoke will be sucked into a tube, where the tube has a small hose at the end, then the smoke is released at the end of the hose, where the end of the hose is soaked in a container containing water, where the air will be filtered. The results of the filter are sucked back by the fan or fan in another room. If the smoke level has fallen below the threshold of $140 \mathrm{ppm}$, the fan will automatically die.
\end{abstract}

Keywords: Sensor Smoke, Smoke Filters, Fan Control, Automatic.

\begin{abstract}
Abstrak
Berawal dari kejadian di pulau Sumatera yang sering mengalami kebakaran hutan dan mengakibatka timbulnya kabut asap yang dapat menganggu saluran pernapasan pada makhluk hidup terutama pada manusia. Sehingga mengakibatkan timbulnya penyakit seperti ispa, sesak nafas, dan penyakit lainnya. Hal ini diakibatkan oleh udara yang tercemar karena konsentrasi oksigen $\left(\mathrm{O}_{2}\right)$ hanya beberapa persen saja dibanding udara yang mengandung karbon dioksida $\left(\mathrm{CO}_{2}\right)$, karbon monoksida $(\mathrm{CO})$, sulfida $\left(\mathrm{S}_{2}\right)$ dan zat hasil pembakaran lainnya. Sensor asap berguna untuk mengaktifkan fan pada alat penyaring asap secara otomatis, Fan berfungsi sebagai penghisap asap untuk diteruskan pada ruangan tempat penyaringan asap. Cara kerja alat ini yaitu, saat sensor membaca kadar asap pada alat lebih dari 140 ppm, maka relay yang terhubung pada kipas akan aktif dan membuat kipas berputar. Setelah kipas atau fan hidup, maka asap yang ada akan terhisap ke dalam sebuah tabung, dimana tabung tersebut memiliki slang kecil di ujungnya, lalu asap tersebut dikeluarkan di ujung slang, dimana ujung slang direndam ke dalam wadah yang berisikan air, disanalah udara akan disaring. Hasil dari penyaringan tersebut dihisap kembali oleh kipas atau fan di ruangan yang lain. Jika kadar asap telah turun di bawah ambang batas yaitu 140 ppm, maka otomatis fan akan mati.
\end{abstract}

Kata kunci: Sensor asap, Penyaring Asap, Kontrol Fan, Otomatis

\section{Pendahuluan}

Energi bagi kehidupan manusia baik untuk kegiatan industri, kegiatan komersial maupun dalam kehidupan rumah tangga sehari-hari. Energi listrik dibutuhkan untuk kebutuhan penerangan dan juga proses produksi yang melibatkan barang-barang elektronik dan mesin industri. Mengingat begitu besar dan pentingnya manfaat energi listrik sedangkan sumber energi pembangkit listrik terutama yang berasal dari sumber daya tak terbarui keberadaannya terbatas, maka untuk menjaga kelestarian sumber energi ini perlu upayakan langkah-langkah strategis yang dapat menunjang penyediaan energi listrik secara optimal dan terjangkau.

Saat ini, ketersediaan sumber energi listrik tidak mampu memenuhi peningkatan kebutuhan listrik Indonesia. Terjadinya pemutusan sementara dan pembagian energi listrik secara bergilir merupakan dampak dari terbatasnya energi listrik yang dapat disalurkan oleh PLN. Hal ini terjadi karena laju pertambahan sumber energi baru dan pengadaan 
pembangkit tenaga listrik tidak sebanding dengan konsumsi listrik[1].

Salah satu upaya untuk mengatasi krisis energi adalah mengurangi ketergantungan terhadap sumber energi fosil dengan cara memanfaatkan sumber energi alternatif atau pun dengan mengembangkan teknologinya. Salah satu bentuk pengembangan teknologinya berupa memodifikasi alternator. Alat yang di buat untuk tugas akhir sebelumnya menggunakan komponen yang sesuai dengan hasil yang diinginkan. Namun setelah pembuatan nya alat ini belum dilakukan pengujian sebagai pembuktian untuk mendapatkan data yang akurat tentang kinerja dan efesiensi yang dibutuhkan. Komponen yang digunakan sesuai dengan energi yang masuk dan mampu menghasilkan daya listrik yang dibutuhkan. Dari penjelasan di atas maka dari itu penulis akan mengangkat judul "perakitan sensor asap pada alat penyaring asap untuk mengontrol fan secara otomatis " yang bertujuan untuk mengetahui kondisi optimum dari putaran terhadap daya listrik yang dihasilkan dan sebagai pengembangan teknologi pembangkit listrik agar dapat dimanfaat untuk listrik rumah tangga[2].

Asap adalah suspense partikel kecil di udara (aerosol) yang berasal dari pembakaran yang tidak sempurna dari suatu bahan bakar[3]. Asap umumnya merupakan produk samping yang tak diinginkan dari api.

Asap dihasilkan oleh hasil pembakaran yang tidak sempurna, pembakaran tak sempurna ini disebabkan oleh oksigen yang tidak cukup untuk membakar bahan bakar sepenuhnya menjadi karbon dioksida $\left(\mathrm{CO}_{2}\right)$ dan air $\left(\mathrm{H}_{2} \mathrm{O}\right)$. Pembakaran adalah suatu runutan reaksi kimia antara suatu bahan bakar dan suatu oksida, disertai dengan produksi panas yang disertai cahaya dalam bentuk pendar dan api. Dalam suatu reaksi pembakaran lengkap, suatu senyawa bereaksi dengan zat pengosidasi, dan produknya adalah senyawa dari tiap elemen dalam bahan bakar dengan zat pengoksidasi[4]. Contoh yaitu reaksi oksidasi pada alkana. Alkana sukar dioksidasi oleh oksidator lemah atau agak kuat, tetapi mudah dioksidasi oleh oksigen dari udara bila dibakar. Oksidasi yang cepat dengan oksigen yang akan mengeluarkan panas dan cahaya disebut dengan pembakaran. Hasil oksidasi dari alkana adalah gas karbon dioksida dan sejumlah air. Sebelum terbentuknya produk akhir oksidasi alkana berupa $\mathrm{CO}_{2}$ dan $\mathrm{H}_{2} \mathrm{O}$, terlebih dahulu terbentuk alkohol, aldehid dan karboksilat. Alkana terbakar dalam keadaan oksigen berlebihan dan reaksi ini menghasilkan sejumlah kalor (eksoterm). Berikut contoh reaksi pada alkana yaitu zat metana.

\section{Sensor Asap ( MQ - 2 )}

Sensor gas asap (MQ - 2) ini mendeteksi konsentrasi gas yang mudah terbakar di udara serta asap dan output membaca sebagai tegangan analog[5]. Sensor gas asap (MQ-2) dapat langsung diatur sensitifitasnya dengan memutar trimpot. Sensor ini biasa digunakan untuk mendeteksi kebocoran gas baik di rumah maupun di industri. Gas yang dapat dideteksi diantaranya : LPG, i-butane, propane, methane ,alcohol.

a. Spesifikasi Sensor Asap ( MQ - 2 ) :

1. 200 - 5000p. Catu daya pemanas : 5V AC/DC

2. Catu daya rangkaian : 5VDC

3. Range pengukuran : pm untuk LPG, propane
a. 300 - 5000ppm untuk butane
b. $5000-20000 p p m$ untuk methane
c. $300-5000$ ppm untuk Hidrogen
d. 100 - 2000ppm untuk alcohol

b. Luaran : analog (perubahan tegangan)

Sensor ini dapat mendeteksi konsentrasi gas yang mudah terbakar di udara serta asap dan keluarannya berupa tegangan analog. Sensor dapat mengukur konsentrasi gas mudah terbakar dari 300 sampai 10.000 sensor ppm. Dapat beroperasi pada suhu dari $-20^{\circ} \mathrm{C}$ sampai $50^{\circ} \mathrm{C}$ dan mengkonsumsi arus kurang dari $150 \mathrm{~mA}$.

\section{Metode Penelitian}

Pembuatan tugas akhir ini membutuhkan alat dan bahan sebagai hal utama dalam pembuatan. Adapun alat dan bahan yang akan digunakan pada pengerjaan tugas akhir tersebut dapat diuraikan sebagai berikut :
Alat
1. Pisau potong
2. Kikir
3. Gergaji besi
4. amplas

Bahan

1. Acrilic

2. Kabel jumper

3. Arduino

4. Relay Modul

5. Protoboard

6. Paku keling

7. Plat Siku Platinum

8. Sensor Asap Mq 2

9. LCD $16 \times 2$

10. IC LCD $16 \times 2$ module

Pembuatan alat ini bertujuan untuk dapat memberikan solusi kepada daerah atau masyarakatnya yang masih belum terjangkau dengan jaringan listrik PLN, Maka dari pada itu penulis bermaksud untuk mengangkat sebuah tugas akhir yang berjudul "Perakitan Sensor Asap pada Alat Penyaring Asap Untuk Mengontrol Fan Secara Otomatis". Sebagai alat yang bisa menghasilkan energi listrik yang dapat digunakan lansung bagi masyarakat.

\section{Hasil dan Pembahasan \\ Pembuatan Box Panel Untuk Kedudukan Komponen}

Box panel pada alat ini menggunakan bahan acrilic,acrilic yang digunakan memiliki ketebalan $2 \mathrm{~mm}$. Adapun langkah-langkah dalam membuat box panel yaitu sebagai berikut : 
- Mengukur acrilic yang dibutuhkan sebagai dudukan untuk sensor

Contoh dapat dilihat pada Gambar 1 di bawah ini:

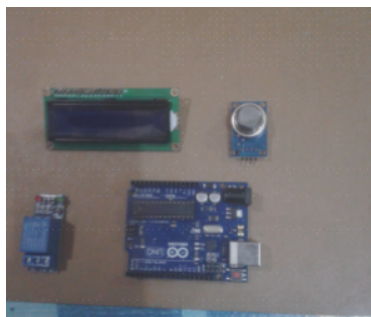

Gambar 1. Menyesuaikan Acrilic Dengan Komponen

- Memotong acrilic sesuai ukuran yang telah ditentukan

Dengan menggunakan pisau potong khusus acrilic dan penggaris besi sebagai pembatas. Contoh dapat dilihat pada Gambar 2.

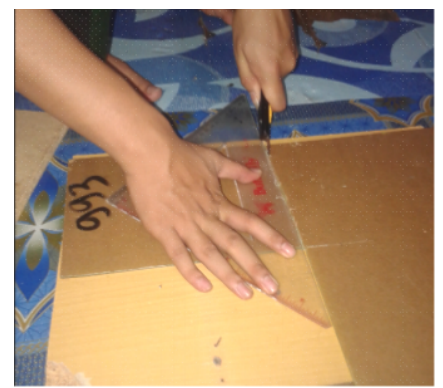

Gambar 2. Pemotongan Acrilic

- Acrilic yang telah di potong dengan ukuran alas $21,5 \times 15,5 \times 1 \mathrm{~cm}, \quad$ sisi depan $2 \times 21,5 \times 10 \times 1 \mathrm{~cm}, \quad$ sisi Samping $2 \times 15,5 \times 10 \times 1 \mathrm{~cm}$ ditumpuk pada suatu tempat dan siap disambung.

Contoh dapat dilihat pada Gambar 3.

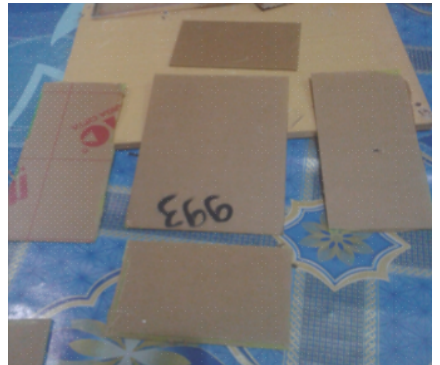

Gambar 3.Acrilic yang Telah Dipotong

- Menyambung acrilic dengan siku alumunium yang telah ditentukan ukurannya.

Dapat dilihat pada Gambar 4.

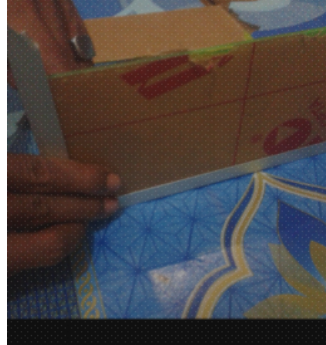

Gambar $4 . \quad$ Menyambung

- Acrilic Dengan Siku Alumunium

- Membor siku alumunium dan acrilic menggunakan mesin bor tangan. Guna siku alumunium dan acrilic di bor yaitu sebagai tempat pemasangan paku tembak.

- Pemasangan paku tembak pada siku alumunium dan acrilic untuk menhubungkan masing-masing sisi pada acrilic untuk membuat box panel.

- Setelah seluruh komponen box panel dipasang, pembuatan Box panel telah selesai dan dapat dipasang atau diletakkan komponen sensor asap.

\section{Hasil Perakitan}

Setelah dilakukan perakitan sensor asap, mulai dari box panel menggunakan bahan acrilic serta siku alumunium dengan perekat paku tembak. Selanjutnya dilakukan perakitan inti atau komponen utama pada alat ini yaitu perakitan sensor asap. Dimana sensor ini nantinya akan digunakan Untuk menghidupkan kipas pada alat penyaring asap secara otomatis. Alat penyaring asap ini memiliki 3 ruang, ruang pertama tempat berkumpulnya asap, dimana ruang pertama memiliki kipas yang berfungsi sebagai penghisap asap, lalu ruang kedua yang berfungsi sebagai penyaring asap agar bersih, lalu yang terakhir ruangan hasil dari penyaringan tersebut

\section{Kesimpulan}

Setelah melakukan perakitan serta pengujian alat, maka didapat beberapa kesimpulan sebagai berikut :

1. Sensor asap membuat kerja alat penyaring asap lebih efisien, karena sebelumnya manual, telah menjadi otomatis karena menggunakan sensor asap, sehingga kita tidak perlu lagi sering-sering menghidup matikan alat tersebut.

2. Alat penyaring asap akan otomatis menyala ketika kadar asap di atas 140 ppm,karena fan hidup pada saat kadar asap pada LCD menunjukkan angka $140 \mathrm{ppm}$ atau lebih.

3. Kita tidak akan mengetahui kadar asap pada sensor jika tidak menggunakan LCD 16x2 pada panel box. Karena LCD berfungsi sebagai visualisasi berapa kadar asap yang terdeteksi pada sensor.

4. Pembuatan program sensor asap untuk menghidupkan fan secara otomatis berhasil membuat fan hidup dan mati secara otomatis. 
5. Hasil perakitan sensor asap berjalan dengan baik, dan komponen-komponen yang dipasang bekerja sesuai fungsinya.

\section{Daftar Rujukan}

[1] Redi, Guntara. 2016.Analisa Potensi Waduk Malahayu Sebagai Pembangkit Listrik Tenaga Mikrohidro. Tugas Akhir. Yogyakarta: Jurusan Teknik Elektro. Fakultas Teknik. Universitas Muhammadiyah Yogyakarta.

[2] Attazaka, Fardana. 2013."Kipas Angin Saklar Otomatis dengan MenggunakanSensor Suhu dan Inframerah berbasis MikrokontrollerAVR Atmega16".Laporan Akhir Tidak dipublikasikan, Politeknik NegeriSriwijaya.

[3] Priasiando.2009.Aplikasi Sensor Asap dan Suhu Sebagai Alarm dan Pemadam Kebakaran Berbasiskan Mikrokontroller
(Bagian Input danControl).Padang:Politeknik Universitas Andalas.

[4] Fowles,Jefferson and Michael Bates.2000.Chemical constituents, cigarettes \& cigarette smoke. http://www.moh.govt.nz/moh.nsf/pagescm/1003/\$File/chemica lconstituentscigarettespriorities.pdf.

[5] Kurniawan, E., Suhery, C., dan Triyanto, D.,2013 "Sistem Penerangan Rumah Otomatis dengan Sensor Cahaya Berbasis Mikrokontroler", Skripsi S1, Universitas Tanjungpura, .

[6] Desyantoro, E., Rochim, A.F., dan Martono, K.T.2015, "Sistem Pengendali Peralatan Elektronik Dalam Rumah Secara Otomatis Menggunakan Sensor PIR, Sensor LM35, dan Sensor $L D R$ ",Skripsi S1, Universitas Diponegoro,. 